\title{
Lateral Displacement And Shear Lag Effect Of High-Rise Buildings With Diagrid SystemThat Is Constructed Above A Frame
}

\author{
Roslida Abd. Samat ${ }^{1, *}$, Fong Teng Chua ${ }^{1}$, Nur Akmal Hayati Mohd Mustakim ${ }^{1}$, Fatin \\ Izzaidah Anuar ${ }^{1}$, Sariffuddin Saad ${ }^{1}$, and Suhaimi Abu Bakar ${ }^{1}$ \\ ${ }^{1}$ Faculty of Civil Engineering, Universiti Teknologi Malaysia, 81310 Skudai, Johore, Malaysia
}

\begin{abstract}
Diagrid system has gained a wide acceptance in the design of tall buildings due to its many advantages including its high structural efficiency in resisting both gravity and lateral loads. Most diagrid structures that had been studied have full triangulated members from the ground level to the top of the buildings where comparison in the effectiveness in minimizing the lateral displacement was often made between structures with full diagrid, frame and outrigger system. Nevertheless, no study has been performed on the effectiveness of the diagrid that is constructed above a frame system. The objective of this research is to understand the behavior of the lateral displacement and shear lag effect due to wind load when the diagrid structure is constructed above a frame. Models of sixty storey buildings were analyzed by using Staad.Pro software. The level where the diagrid members started and the spacing of vertical base columns of the frame were altered. The lateral displacement and shear lag effect resembled closely of those of the model of full diagrid when the diagrid was started at level 3 , and the vertical base columns were uniformly spaced at 6 metres.
\end{abstract}

\section{Introduction}

The struggle to control the lateral displacement of tall buildings has caused the emergence of many tall building systems. The latest tall building system which now has become favourable among today's designer is diagrid system. Diagrid system is composed of many diagonal structures that connect together to form a triangulated shape or can be seen as grid shape. The combination of "diagonal" and "grid" words produces the term "diagrid" which refers to a structural system that is single-thickness in nature and gains its structural integrity through the use of triangulation [1]. Unlike the braced tube structure, diagrid structure has no vertical columns present and thus is considered as the evolution of braced tube structure [2]. Diagrid system that is favoured due to its structural efficiency and aesthetic potential $[3,4]$, is categorized as exterior structure, which is a lateral load resisting system that is located along the building perimeter. Diagrid enables the architect to design a building with some unique elements such as irregular angle and nonlinear shape as

*Corresponding author: roslida@utm.my 
portrayed in buildings like Swiss Re (30 St. Mary Axe) in London, Capital Gate in Abu Dhabi and CCTV in Beijing. [5] studied the structural performance of complex-shaped tall buildings such as twisted, tilted and freeform towers that were designed with diagrid system.

The aesthetically unique design of skyscraper that diagrid provides is mainly due to its free of exterior columns [6]. Since diagrid system allows the elimination of almost all the vertical columns, this system is able to provide variety of open floor plans. Diagrid building is an efficient system because it is able to achieve the same displacement as the displacement of buildings that have other tall building systems with significant reduction of the steel volume. [7] reported that the implementation of diagrid system to "The Bow " or Encana Tower that is located in Calgary in Western Canada had managed to reduce approximately 20 percent of the structural steel weight when compared to a building with a conventional moment frame system.

Exterior structural systems including diagrid are designed to control the lateral displacement of tall building. The taller the building is the higher the wind load is as wind speed increases parabolically with height from ground. Damage to non-structural elements such as cracking in reinforced walls, damage to lightweight partitions and impaired operation of windows are common examples of the effect of excessive lateral displacement of tall building [8]. Thus, the control of lateral displacement is a serious issue in the design of tall building. A building should not sway horizontally more than $\mathrm{H} / 500$ to consider the design criteria that are strength, serviceability, stability and human comfort [9]. [10] recommends the drift limit to be on the order of $1 / 600$ to $1 / 400$ of the building or story height.

Another important issue in the design of high rise building is shear lag. Shear lag is caused by the lack of shear stiffness that reduces the structural effectiveness of the framed tube. [11] stated that the diagrid tube structure is one of the structural solution to minimize shear lag effect. [12] proved that diagrid structures indeed lower the shear lag compared to frame tube structure. However, the increase of the slope of the braces of diagrid increases the shear lag and becomes more rapid when the angle is higher than $70^{\circ}$. Interestingly, shear lag does not correlate with the lateral displacement of high rise building [12].

Full diagrid structures are buildings that have diagrid system being constructed from the ground floor to the top of the building. Most diagrid buildings in the world are full diagrid structures, for example, Swiss Re (30 St. Mary Axe) in London, CCTV in Beijing, United Steelworkers Building in Pittsburgh, USA and Tornado Tower in Doha, Qatar. There are a few buildings in the world that employ combination of diagrid system and other tall building systems at their perimeter, for example, Lotte World Tower in Seoul, Korea which has its diagrid being constructed only from the 107th floor to the top [13] and Hearst building in New York which has its diagrid system being supported by mega columns and super-diagonals that are constructed from the foundation to the 10th floor [14].

Many studies on the performance of full diagrid structures where the diagrid system begins from the ground floor to the top of building have been conducted. However, there is no systematic research that has been carried out on tall building that has diagrid that are constructed above a frame structure. Thus, the objective of this study is to find the effect of constructing a diagrid system above a frame to the lateral displacement and shear lag of a sixty storey building due to wind load. The parameters of the vertical columns of the frame that transmitted the force from the diagrid system to the foundation were varied to investigate how they influenced both the lateral displacement and shear lag. The parameters that were manipulated are the level of where the diagrid system started, the spacing of the columns of the frame and the arrangement of the columns of the frame. 


\title{
2 Methodology
}

The structural analysis software, STAAD.Pro V8i was used to analyse all models statically. All elements in the buildings such as beams, columns and diagrid truss were modelled by using line element where each node has three degrees of freedom which are independent vertical motion, independent horizontal motion and independent rotational motion.

Generally, each model has 60 stories with $4 \mathrm{~m}$ storey height and $36 \mathrm{~m} \times 36 \mathrm{~m}$ square floor plan as shown in Figure 1. All columns were reinforced concrete columns. The size of the internal column is $1200 \mathrm{~mm} \times 1200 \mathrm{~mm}, 900 \mathrm{~mm} \times 900 \mathrm{~mm}$ and $600 \mathrm{~mm} \times 600 \mathrm{~mm}$ at Level 1 to 20, Level 21 to 40 and Level 41 to 60, respectively. Full diagrid model did not have any external columns, while the models with the combination of frame and diagrid systems did have external columns in the frame system part, where the dimensions of those columns were varied such that the total cross sectional area of the columns remained the same for all models.

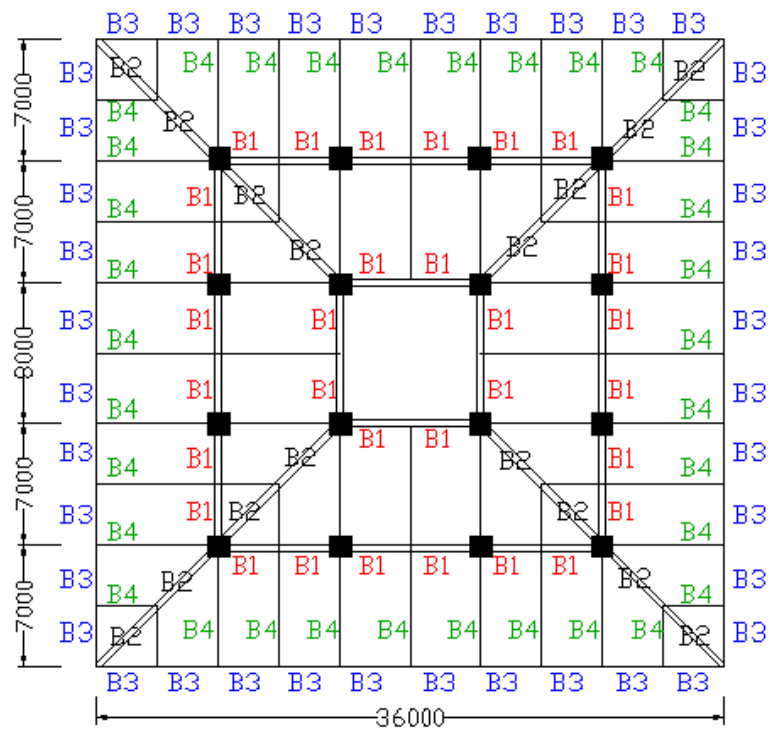

\author{
Beam specification : \\ B1 $-650 \mathrm{~mm} \times 250 \mathrm{~mm}$ \\ reinforced concrete beam \\ B2 - $750 \mathrm{~mm} \times 350 \mathrm{~mm}$ \\ reinforced concrete beam \\ B3 - $700 \mathrm{~mm} \times 700 \mathrm{~mm} \times 25$ \\ mm thick steel hollow tube \\ B4 - UB 406x140x53 steel beam
}

Fig. 1 Typical plan view of all Building Models.

The angle of the triangulated members was uniform and was approximately about 69 degrees, where one module of diagrid was equalled to two storeys of the building. [15] stated that, 69 degrees is the near optimum angle for 60 -story high building with diagrid structure. Furthermore, the intersection between the diagonal members was pin-connection so that axial action merely carries the transverse shear and moment. The diagonal members had pinned supports, while the external and internal columns had fixed-end supports. Models of combination of diagrid and frame systems used reinforced concrete beams of $400 \mathrm{~mm} \times 1000 \mathrm{~mm}$ as the transfer beams that transmitted the axial forces in the diagrid system to the frame system

Three parameters that were studied in combination of diagrid and frame systems are the height of the frame, the spacing of uniformly spaced exterior base columns and arrangement of exterior base columns. Model 1 is a frame model without any diagrid while Model 2 is a fully diagrid building. For the study of the height of frame of models with combination of frame and diagrid system, the frame system was at the lower levels while 
diagrid system was at upper levels where the diagrid started at level 1, 3, 5 and 7, for Model $3 h, 4 h, 5 h$ and $6 h$, respectively, as shown in Figure 2.

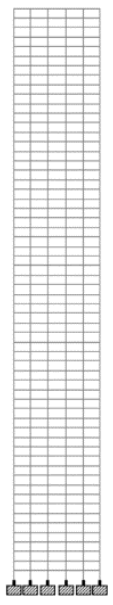

(a)

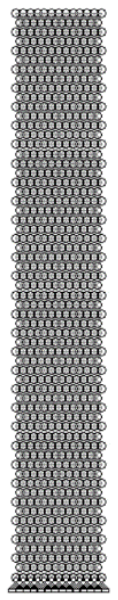

(b)

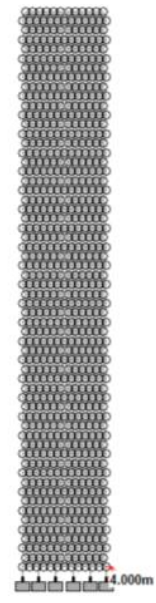

(c)

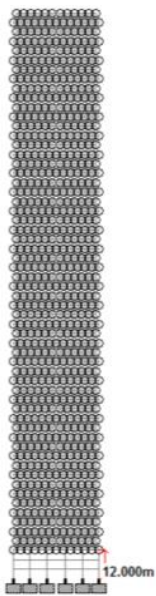

(d)

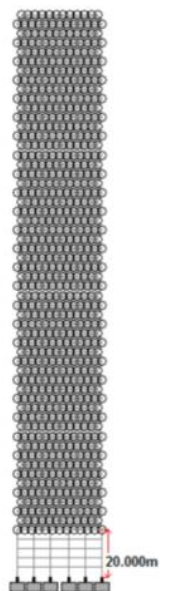

(e)

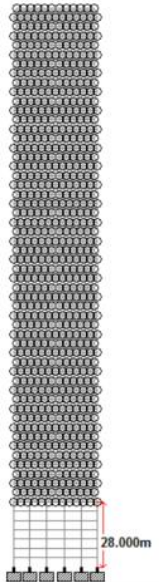

(f)

Fig. 2. Side elevation of 60 storey models (a) Model 1: Frame without diagrid, (b) Model 2h: Diagrid started at G level, (c) Model 3h: Diagrid started level 1, (d) Model 4h: Diagrid started level 3, (e) Model 5h: Diagrid started level 5 and (f) Model 6h: Diagrid started level 7.

Investigation on parameter 2, which is the spacing of uniformly spaced exterior base columns, was performed by varying the spacing between the base columns to $6 \mathrm{~m}, 7.2 \mathrm{~m}$, $9 \mathrm{~m}, 12 \mathrm{~m}$ and $18 \mathrm{~m}$ spacing. The height of the frame is $4 \mathrm{~m}$ and the dimension of the base column building model was varied such that the total cross sectional area of the base columns remained the same for all spacing of the base columns. The third parameter which is the arrangement of the base columns was studied by varying both the spacing and the type of arrangement of the base columns: uniform spacing between the columns (Model $3 r$ ), varying spacing but symmetrical arrangement of the position of the columns (Model $4 r$, $5 r, 6 r$, and $7 r$ ) and varying spacing with non-symmetrical arrangement of the position of the base columns (Model 8r, $9 r$ and 10r).

The wind load was calculated based on the procedure provided in the ASCE7-10. Two wind environments that were considered are Malaysian wind speed which is benign and Hong Kong wind speed which is more aggressive. Determination of the displacement of a building is a serviceability design while the determination of shear lag is a survivability design. Thus, the 3 -second gust wind speed for 10 year return period at $10 \mathrm{~m}$ high for Malaysian and Hong Kong wind environment which is $28.14 \mathrm{~m} / \mathrm{s}$ and $42.48 \mathrm{~m} / \mathrm{s}$, respectively were applied during the analysis for displacement. Analysis for axial forces which was used to observe shear lag had the 3-second gust wind speed for 50 year return period at $10 \mathrm{~m}$ high for Malaysian and Hong Kong wind environment of $33.5 \mathrm{~m} / \mathrm{s}$ and 57.4 $\mathrm{m} / \mathrm{s}$, respectively. The buildings, further, were assumed to be located in an urban area and thus, exposure B as stated in ASCE 7-10 was used.

\section{Results and Discussion}

Results from the dynamic analysis that was performed on all building models show that the lowest natural frequency of all models exceeded $1 \mathrm{~Hz}$. Thus, the buildings are categorized as stiff buildings, and static analysis is sufficient to determine both lateral displacement and 
stresses of the models, as in accordance with building code in United States of America, ASCE 7-10 [10].

\subsection{Lateral Displacement}

The pattern of the lateral displacement is determined under three different conditions : variation of base column height, variation of column spacing and variation of column arrangement.

\subsubsection{Variation of base column height}

The maximum lateral displacement occurred at the top of the building. For both Malaysian and Hong Kong wind environments, the frame model had the largest lateral displacement while the full diagrid structure had the lowest displacement, where the percentage of difference is 66 percent when compared to the displacement of the frame structure. Increasing the height of the frame reduced the percentage of difference slightly, which is $61,60,59$ and 57 percent when the diagrid began at Level 1, 3, 5 and 7, respectively.

\subsubsection{Variation of column spacing}

The larger the base column spacing was, the higher the lateral displacement became, except for base column spacing of $7.2 \mathrm{~m}$. Table 1 shows that the lateral displacement for base column spacing of $7.2 \mathrm{~m}$ was more than the $9 \mathrm{~m}$ spacing, and was almost the same as the lateral displacement for $12 \mathrm{~m}$ base column spacing. This is because the total moment of inertia of the columns for $7.2 \mathrm{~m}$ column spacing is less than total moment of inertia of the $9 \mathrm{~m}$ column spacing despite the total cross sectional area of the base columns are kept the same for all column spacing.

The spacing between the base columns did affect the lateral displacement of the diagrid structure where the percentage of difference of the lateral displacement of the structures when compared to the full diagrid structure is $5.3 \%, 17.4 \%, 10.1 \%, 16.2 \%$ and $28.7 \%$ for the base column spacing of $6 \mathrm{~m}, 7.2 \mathrm{~m}, 9 \mathrm{~m}, 12 \mathrm{~m}$ and $18 \mathrm{~m}$. The lateral displacement is the least for the base columns with the least spacing which is $6 \mathrm{~m}$ and the highest for base column spacing of $18 \mathrm{~m}$ which is the largest spacing.

Table 1. Moment of Inertia and Maximum Lateral Displacement of the models with different Base Column Spacing.

\begin{tabular}{|c|c|c|}
\hline Column Spacing (m) & $\begin{array}{c}\text { Moment of Inertia } \\
\left(\mathrm{x} 10^{15} \mathrm{~mm}^{4}\right)\end{array}$ & $\begin{array}{c}\text { Maximum Lateral } \\
\text { Displacement }(\mathrm{mm})\end{array}$ \\
\hline 6.0 & 9.153 & 141.1 \\
\hline 7.2 & 9.032 & 157.3 \\
\hline 9.0 & 9.606 & 147.6 \\
\hline 12.0 & 9.496 & 155.7 \\
\hline 18.0 & 9.367 & 172.4 \\
\hline
\end{tabular}

\subsubsection{Variation of column arrangement}

The combined frame and diagrid system with $6 \mathrm{~m}$ uniformly spaced base columns had slightly larger lateral displacement when compared to a full diagrid building in the Hong Kong wind environment as shown in Table 2. The total moment of inertia at the ground floor differs for different arrangement of the base columns. The lateral displacement is influenced by the value of moment of inertia and the spacing of the columns near to the 
corner of the buildings. Model $7 r$ which had the smallest moment of inertia and the largest spacing of the columns near to the corner of the building had the largest lateral displacement while Model $3 r$ which had one of the largest of moment inertia and small spacing of the column near to the corner of the building had the smallest lateral displacement. Model $8 r$ and $9 r$ which had the same moment of inertia and the same column spacing at the corner of the building had similar deflection. Model $5 r, 6 r$ and $10 r$ had the same moment of inertia, but Model 6 which had the largest column spacing at the corner of the building among the three models had the largest lateral displacement. In contrast, Model $10 r$ had the smallest column spacing at the corner when compared to Model $5 r$ and $6 r$, and thus had the smallest lateral displacement among the three models.

Table 2. Lateral displacement and total moment of inertia at ground level for different arrangement of the base columns of frame-diagrid models

\begin{tabular}{|l|c|c|}
\hline \multicolumn{1}{|c|}{ Model - (Spacing of Base Column) } & $\begin{array}{c}\text { Lateral } \\
\text { Deflection } \\
(\mathrm{mm})\end{array}$ & $\begin{array}{c}\text { Moment of } \\
\text { inertia }\left(\mathrm{mm}^{4}\right)\end{array}$ \\
\hline 1 - Frame & 399.507 & \\
2 - Full Diagarid & 134.687 & \\
$3 r$ - Diagrid-frame (6.0m-6.0m-6.0m-6.0m-6.0m-6.0m) & 141.777 & $4.15 \times 10^{12}$ \\
$4 r$ - Diagrid-frame (4.0m-4.0m-10.0m-10.0m-4.0m-4.0m) & 150.312 & $4.16 \times 10^{12}$ \\
$5 r$ - Diagrid-frame (7.0m-11.0m-11.0m-7.0m) & 157.862 & $2.77 \times 10^{12}$ \\
$6 r$ - Diagrid-frame $(11.0 m-7.0 m-7.0 m-11.0 m)$ & 160.731 & $2.77 \times 10^{12}$ \\
$7 r$ - Diagrid-frame $(14.0 m-8.0 m-14.0 m)$ & 174.708 & $2.08 \times 10^{12}$ \\
$8 r$ - Diagrid-frame $(6.0 m-8.0 m-10.0 m-12.0 m)$ & 152.022 & $2.43 \times 10^{12}$ \\
$9 r$ - Diagrid-frame $(12.0 m-10.0 m-8.0 m-6.0 m)$ & 151.753 & $2.43 \times 10^{12}$ \\
$10 r$ - Diagrid-frame $(6.0 m-11.0 m-13.0 m-6.0 m)$ & 150.895 & $2.77 \times 10^{12}$ \\
\hline
\end{tabular}

\subsection{Shear Lag Effect}

Shear lag effect can be recognized by the uneven distribution of vertical axial forces in the peripheral columns that are located at the flange of the building or by the nonlinear distribution of the axial force in the peripheral columns that are located at the web of the buildings.

\subsubsection{Variation of base column height}

The stress distribution of the columns that were located on the flange panel at the first storey $(z / H=0)$ of all models, showed positive shear lag effect, where the columns at the edge of flange panel experienced larger axial stresses compared to the middle columns. The axial stress distribution of the columns was almost uniform at fifteenth storey, and became uniform at thirtieth storey and above.

Furthermore, the overturning moment caused by the lateral load formed the tensile axial stress at the windward face and compressive stress at the leeward face. However, the weight of the building balanced the tensile stress that resulted in minimal value of compressive stress at the windward face, while augmented the compressive stress at the leeward face. As a result, the columns at the two corners of leeward face of the building had 
very large axial load, contrary to the other columns at the two corners of the windward face of the building that resisted minimal amount of axial load.

Shear lag effect was reduced significantly and the value of the stress was lowered when full diagrid building is adopted instead of a frame building. The largest stress at the perimeter column which is located at the corner of the leeward face is reduced by 64 percent that is from $51300 \mathrm{kN}$ to $18700 \mathrm{kN}$ when full diagrid building was used instead of a frame building. The value of stresses that were resisted by the full diagrid building in flange panel and web panel are the least among all models.

However, when the frame is combined with the diagrid, where the diagrid started at the upper level, the effect of the positive shear lag increased significantly. The largest stress at the perimeter columns had the maximum value of $54240 \mathrm{kN}$ at columns at the leeward face for Model 3 where the diagrid started at Level 1. The value of stress in these columns at the leeward face was reduced by 7 percent to $50670 \mathrm{kN}$, by 10 percent to $48960 \mathrm{kN}$ and by 12 percent to 47890 when the diagrid started at Level 3, Level 5 and Level 7, respectively. In addition, a minor negative shear lag effect where the stress in the columns at the corner was lower than the stress in the columns at the middle, occurred at the fifteenth storey $(z / H=$ 0.25 ) for all models with combination of diagrid and frame system.

Shear lag between the models can also be compared by using the factor $f$, which is the ratio between the axial forces at the corner columns to the axial forces at the middle of the panel [12]. A factor more than 1.0 indicates a positive shear lag which occurred at the base of the models; while a factor less than 1.0 indicates negative shear lag which usually occurred at mid-height of the building models.

The use of full diagrid system reduced both the deflection and the shear lag significantly (Table 3). However, when one storey high frame is added below the diagrid system, the shear lag increased tremendously. There was a slight increase of displacement but was still very much lower than the deflection of a frame building. Increasing the height of frame below the diagrid reduced the shear lag, but increased the deflection slightly. The addition of one storey high frame below the diagrid system caused a sudden nonlinear distribution forces in the base columns as these columns carried the loading from the entire fifty-nine storey high of axial forces. As the height of the frame was increased, the forces from the diagrid system above it were redistributed in a better flow to the base column.

Table 3. Deflection and shear lag ratio for models with different height of frame under the diagrid system.

\begin{tabular}{|c|c|c|c|c|c|c|c|}
\hline \multirow{3}{*}{ Model } & \multirow{3}{*}{$\begin{array}{c}\text { Level } \\
\text { where } \\
\text { diagrid } \\
\text { started }\end{array}$} & \multicolumn{3}{|c|}{ Malaysia Wind Load Case } & \multicolumn{3}{|c|}{ Hong Kong Wind Load Case } \\
\hline & & \multirow{2}{*}{$\begin{array}{c}\text { Displacement, } \\
x \text {-direction } \\
(\mathrm{cm}) \\
\end{array}$} & \multicolumn{2}{|c|}{ Shear Lag Ratio, $f$} & \multirow{2}{*}{$\begin{array}{c}\text { Displacement, } \\
x \text {-direction } \\
(\mathrm{cm})\end{array}$} & \multicolumn{2}{|c|}{ Shear Lag Ratio, $f$} \\
\hline & & & Base & $\begin{array}{c}\text { Mid } \\
\text { Height }\end{array}$ & & Base & $\begin{array}{c}\text { Mid } \\
\text { Height }\end{array}$ \\
\hline 1 & $\begin{array}{c}\text { No } \\
\text { diagrid }\end{array}$ & 17.47 & 1.14 & 0.97 & 39.87 & 1.39 & 0.96 \\
\hline 2 & Ground & 5.87 & 1.18 & 0.80 & 13.42 & 1.30 & 0.79 \\
\hline $3 h$ & 1 & 6.88 & 1.64 & 0.90 & 15.70 & 1.70 & 0.87 \\
\hline $4 h$ & 3 & 6.87 & 1.48 & 0.90 & 15.90 & 1.57 & 0.87 \\
\hline $5 h$ & 5 & 7.24 & 1.39 & 0.90 & 16.53 & 1.50 & 0.87 \\
\hline $6 h$ & 7 & 7.58 & 1.33 & 0.90 & 17.31 & 1.46 & 0.87 \\
\hline
\end{tabular}

\subsubsection{Variation of column spacing}

The deflection increased slightly when the diagrid was combined with the frame that had uniform spaced columns, the shear lag factor generally decreased to a value close to 1 , which indicates an almost uniform stress for all perimeter columns at the base (Table 4). However, when the spacing was $7.2 \mathrm{~m}$, both the lateral deflection and the shear lag ratio 


\section{EACEF 2017}

increased more than when full diagrid system was used. This is the case when the moment inertia is the least compared to other models with different base column spacing and, its perimeter columns being aligned to the internal columns. This alignment disrupts the transmission of the axial force of the columns at the corner to the adjacent perimeter columns and thus causing the columns at the corner to bear large axial force

Table 4. Lateral Deflection and Shear Lag Ratio for Different Building Model.

\begin{tabular}{|c|c|c|c|c|}
\hline \multirow{2}{*}{ Type of Model Building } & \multirow{2}{*}{$\begin{array}{c}\text { Model } \\
\text { Number }\end{array}$} & \multirow{2}{*}{$\begin{array}{c}\text { Deflection } \\
(\mathrm{cm})\end{array}$} & \multicolumn{2}{|c|}{ Shear Lag Ratio $f$} \\
\cline { 4 - 5 } & & & Base & Mid-height \\
\hline Full Frame & 1 & 39.87 & 1.390 & 0.960 \\
\hline Full Diagrid & 2 & 13.42 & 1.294 & 0.792 \\
\hline Modified Diagrid with 6m spacing & $3-u$ & 14.11 & 1.091 & 0.875 \\
\hline Modified Diagrid with 7.2m spacing & $4-u$ & 15.73 & 1.426 & 0.872 \\
\hline Modified Diagrid with 9m spacing & $5-u$ & 14.76 & 1.032 & 0.874 \\
\hline Modified Diagrid with 12m spacing & $6-u$ & 15.57 & 0.979 & 0.872 \\
\hline Modified Diagrid with 18m spacing & $7-u$ & 17.24 & 0.946 & 0.868 \\
\hline
\end{tabular}

\subsubsection{Variation of column arrangement}

Figure 3 shows the distribution of axial stress of the columns at the flange panel for model $3 r, 4 r, 5 r$ and $6 r$.
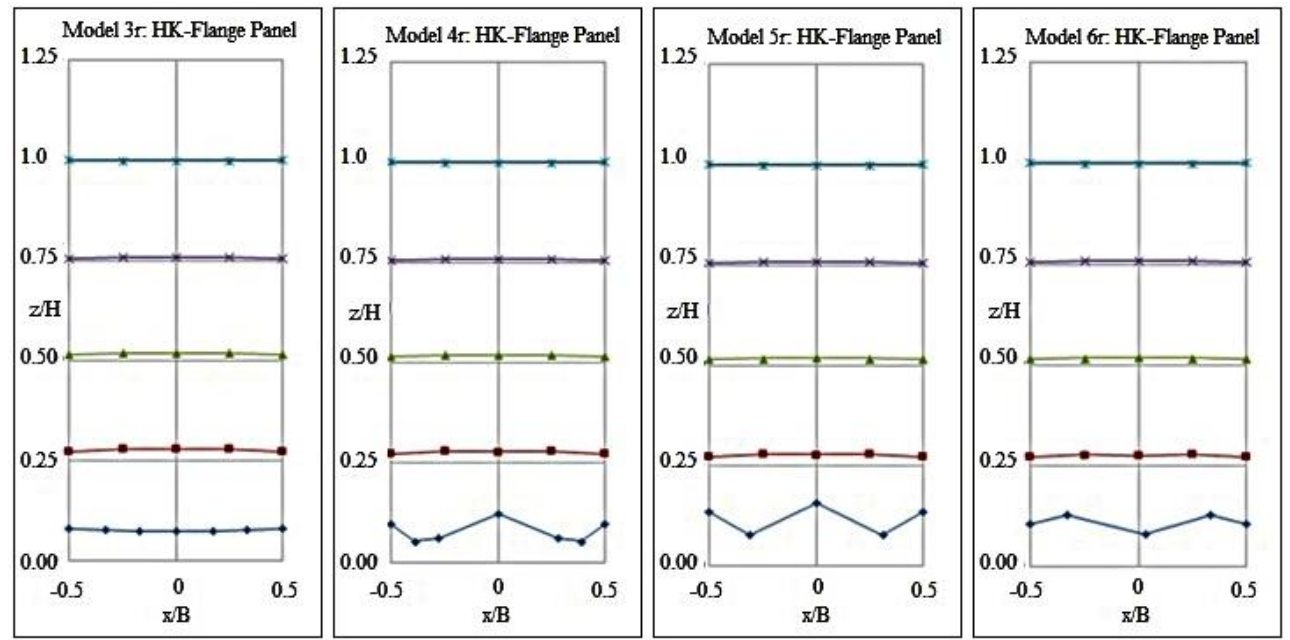

Fig. 3. Shear lag effect on the four models: $3 r, 4 r, 5 r$ and $6 r$, with combination of diagrid and frame with different base column arrangement in the flange panel of the model in Hong Kong wind environment

Model $3 r$ has the most uniform distribution of axial stress at ground level among all the models and has the lowest axial stress among the models that have different arrangement of the base columns. Generally, at mid height of the building where $\mathrm{z} / \mathrm{H}=0.5$, the pattern of axial forces distribution shows the negative shear lag effect for all models regardless the arrangement of the base columns. 


\section{Conclusion}

The use of diagrid system, either full diagrid or combined with frame at lower levels reduced the lateral displacement significantly, when compared to full frame structure. The percentage of reduction of the lateral displacement ranged from 56 percent to 66 percent. The difference of lateral displacement between the models where diagrid started at upper level with fully diagrid model is minor, which is less than $4 \mathrm{~cm}$. Diagrid started at level 3 recorded the least displacement when compared to other models with diagrid started at upper level. Base columns with uniform spacing of $6 \mathrm{~m}$ had the least displacement when compared with models of combination of diagrid and frame system that had different spacing value and different arrangement of columns. The reduction of the lateral displacement of the models was 64.5 percent, 56.8 percent and 56.3 percent for $6 \mathrm{~m}$ uniform spacing, $18 \mathrm{~m}$ uniform spacing and non-uniform spacing of $14 \mathrm{~m}-8 \mathrm{~m}-14 \mathrm{~m}$, respectively, when compared to full frame models. It is concluded that lateral displacement increased with increased spacing of the base columns and the non-uniformity of spacing of the base columns.

Shear lag effect was worst at the lowest level of the building where the shear lag ratio is more than one. The two columns at the corner of the building at the leeward face endured the largest axial stresses to resist the overturning moment due to the lateral wind load. The level where the diagrid started affected the shear lag where the worst shear lag occurred when the diagrid started at level 1 . However, as the higher the level where the diagrid started was, the lower the shear lag ratio became. Meanwhile, the shear lag ratio at the ground level of the models of diagrid-frame system with uniformly spaced base columns was close to unity regardless the value of the spacing except when the spacing was $7.2 \mathrm{~m}$. The exterior base columns were aligned with the interior columns when the spacing was $7.2 \mathrm{~m}$ and this reduce the tube action by the exterior columns, and thus, inhibited the axial force from being distributed to the adjacent columns. This phenomena is observed for all models of diagrid-frame combination with different level of where the diagrid started. All of these models had the exterior columns aligned with the interior columns and the shear lag ratio of these models was very much larger compared to other diagrid-frame models where their exterior columns did not align with the interior columns.

Furthermore, the uniform spacing of the base column of models with combination of diagrid and frame system had the least shear lag effect as these models had a uniform distribution of the axial forces among their exterior base columns. In contrast, non-uniform spacing of base column caused the distribution of the axial forces at ground level to become irregular.

As a conclusion, diagrid system combined with frame system decreased the percentage of reduction of the lateral displacement of building when compared to full frame building. However, the value of the decrease of the percentage of reduction of the lateral displacement is very small and thus, the use of the combination of diagrid and frame system is still effective in reducing the lateral displacement of building. Furthermore, the shear lag effect can be reduced by having uniform spacing of the base columns. However, the base columns must not be aligned with the interior columns to avoid the increase of shear lag effect.

Further study on the behaviour of the lateral displacement and shear lag on the combination of diagrid and frame should be done but with the height of the frame increases to 25 percent, 50 percent and 75 percent of the height of the building. The same parameters which are the spacing and arrangement of the exterior columns should be studied.

The study was funded by the Ministry of Education Malaysia and Research Management Centre, Universiti Teknologi Malaysia under Research University Grant No. QJ130000.2622.12J25. 


\section{References}

1. T.M. Boake, Diagrid Structures: Systems, Connections, Details (Birkhauser Verlag $\mathrm{GmbH}, 2014)$

2. S.Yadav, V. Garg, Int. j. civ. struct. eng. res, 3, 394-406 (2015)

3. H. Varsani, N. Pokar, D. Gandhi, IJAREST, 2, 1-4 (2015)

4. K.S. Moon, M.M. Ali, Archit Sci Rev, 50, 205-223 (2007)

5. K.S. Moon, Procedia Eng., 14, 1343-1350 (2011)

6. K.S. Moon, Archit Sci Rev, 51, pp 239-251 (2008)

7. B.Charnish, T.MCDonnell, CTBUH $8^{\text {th }}$ World Congress (2008)

8. L. G. Griffis, ENG J AISC, First Quarter, (1993)

9. P. Jayachandran, National Workshop on High-rise and Tall Buildings (2009)

10. American Society of Civil Engineer, ASCE Standard ASCE/SEI 7-10 Minimum Design Loads for Buildings and Other Structures (2010)

11. B.S.Taranath, Structural Analysis \& Design of Tall Buildings (1988)

12. J. Leonard, Investigation of Shear Lag Effect in Highrise Buildings with Diagrid System (2004)

13. http://www.skyscrapercity.com/showthread.php?t=474259\&page $=293$

14. http://www.fosterandpartners.com/projects/hearst-tower/

15. K.S.Moon, International Journal of Sustainable Building Technology and Urban Development, 2, 37-42 (2011) 